\title{
How to Make Your Feedback Effective?
}

\section{Abdul Hadi}

This short communication may be cited as:

J Saidu Med Coll Swat 2021;11(1):58-60

It is well known that, medical teachers and supervisors are involved in teaching process with under graduate and postgraduate students. During this teaching process, most of them have gone through the process of either giving feedback to the students or receiving feedback from them or from senior faculty members. Most of them don't know a proper technique of giving feedback and most of the time the process is random and disorganized. During this process of feedback majority of the medical teachers and supervisors are unaware of;

How to start giving feedback,

What will be the logical flow of events during the feedback session,

How to highlight the good and bad areas,

How to engage the candidate,

How to invite the candidate for inclusive discussion,

How to do positive criticism on bad areas to avoid personal hurt to the candidate and intimidation,

How to guide the candidate for further improvement,

How to close the session

And how to offer further dialogue.

The aim of this short communication is to make aware the medical teacher regarding different models of feedback, principles of feedback, do's and dont's of feedback and how to make the feedback more effective and result oriented.

Models of Feedback:

\section{Sandwitch Method: ${ }^{1}$}

The steps are;

a. Praise: Explain to the learner/student that what was good and why.

b. Areas of development: Identify the areas of poor performance and do highlight what was wrong. Then suggest the ways and means that how it can be improved? This is crucial phase of feedback, so be specific and do offer examples.

1. Department of Cardiology, Saidu Medical Collegel

Saidu Teaching Hospital, Swat.

Correspondence: Dr. Abdul Hadi, Assistant Professor

Department of Cardiology, Saidu Medical Collegel

Saidu Teaching Hospital, Swat.

Cell: 03339144880EMail: drhadi78@gmail.com c. Positive encouragement: Do emphasise on progressand offer dialogue.

2. Pendleton's Rule: ${ }^{1}$

a. The student states what was done well

b. The observer state what was done well

c. The student states what could be improved

d. The observer state how it could be improved

e. An action plane for improvement is made.

\section{Principles of Feedback}

For effective feedback the following principles may be followed;

1. Helping to clarify what good performance is: One has to clarify to the student that what are the good areas of learning and guide him/her as well to improve upon the weaker areas. ${ }^{2}$

2. Facilitating the development of selfassessment in learning: In feedback, one should also guide the student that its also helpful to contact peer, to discuss how to further improve the learning experiance. ${ }^{2,3}$

3. Delivering high quality information to students about their learning: The teacher/supervisor should provide in-time and effective feedback to the student that will help the student to further refine and improve his/her learning process, to polish his/her learning skills. ${ }^{4}$

4. Encouraging teacher dialogue around learning: One should also encourage the student that after your initial feedback, welcome the student for further guidance and discussion. ${ }^{2,4}$

5. Encouraging positive motivational beliefs and self-esteem: The teacher should appreciate the student as well, where necessary, it will boost the selfesteem of the student and motivate for further learning. ${ }^{5}$

6. Providing opportunities to close the gap between current and desired performance: It should be clearly mentioned in the feedback that, what was required in the learning process, what is 
the gap and guide them that how the gap can be filled. ${ }^{3,5}$

7. Descriptive rather than Judgmental or Evaluative: The teacher should try his/her level best to remain descriptive rather judgmental, and guide the candidate properly. ${ }^{4}$

8. Specific rather than General?: Where necessary one should remain specific and to the point, to improve certain particular areas. $^{4}$

9. Sharing information rather than giving advice: Its very important to guide the student in a way that, they don't feel the feedback as advice, rather in a way of sharing information. ${ }^{4-6}$

10. Solicited/Offered rather than Imposed: During the process of feedback, one should suggest certain improvements, which can improve the student learning; instead of imposing any thing on the student. ${ }^{5,6}$

11. Encourage dialogue around learning: While offering the feedback one should keep the feedback to certain areas so that the feedback can improve the learning process of the student. ${ }^{5,6}$

12. Avoid dishonest or meaningless comments: To the best of the knowledge and competency of the teacher, he/she should avoid any unnecessary comments. $^{5}$

13. It's complicated: As giving feedback is a huge responsibility, so one should observe utmost care to give honest and relevant feedback. ${ }^{2}$

14. Communicate for connection: The teacher and the supervisor should try that their feedback is trust worthy and credible as well. One should try to be empathetic. The teacher should try to his/her best that his/her feedback would be received positively. ${ }^{6}$

15. Timing matters: Timely feedback helps the student a lot, as the student will have enough time to respond again in future, if necessary, so one should finished the feedback well in time. ${ }^{4,6}$

16. Connect feedback to future-oriented goals: One should try to make feedback in a way that it opens for future, not the end. ${ }^{5}$

17. Feedback alone is not enough: The teacher should try that the feedback to the student is action oriented. One should guide the student that which actions are necessary to improve the learning process. ${ }^{4}$

Challenges while Delivering Effective Feedback in Your Practice as a Teacher/Supervisor?

While keeping in mind the principles of feedback, it's a daunting task and has to go on a tight rope to deliver an effective feedback. So it will not be a smooth sailing for a teacher/supervisor and might face certain challenges while delivering feedback, which are highlighted below;

1. Subject Specialist: While giving a formal feedback to a student or a trainee, one should have a better grasp of the topic. I think until and unless one has not a good control of the topic, the teacher/supervisor will not be in a better position to give effective feedback. ${ }^{7}$

2. Be positive and not personal: One has to try through out the feedback process to highlight the wrong things in a positive way, so that the student take it in a positive way and did not feel that he/she have been hurted. ${ }^{6}$

3. Improvement in the learning process: While going through the feedback process, one has to constantly struggle that my feedback should be in a way to improve the learning process of the student. ${ }^{8,9}$

4. Feedback format: One may find it difficult to follow a format for giving feedback, which will help the learner to understand the feedback and will help the student to improve the learning process. ${ }^{4,5}$

5. Be specific: During the feedback process, one may struggling with limiting himself/herself to specific areas of improvement, rather being generalized. ${ }^{8}$

6. To do justice: The feedback will have definitely an impact on student education and even on his/her personality. So one may be struggling to do justice with feedback and the student. ${ }^{9}$

\section{REFERENCES}

1. Pendleton D. The Consultation: An Approach to Learning and Teaching. Oxford Medical Publication. 1984;68-71.

2. Craven RG, Marsh HW, Debus RL. Effects of internally focused feedback on the enhancement of academic self-concept. Journal of Educational Psychology. 1991;83(1):1727. 
3. Ende J. Feedback in Clinical Medical Education. Journal of the American Medical Association. 1983;250(6):777-781.

4. Nicol JD, Macfarlane-Dick D. Formative assessment and self-regulated learning: a model and seven principles of good feedback practice. Journal Studies in Higher Education. 2007;31(2):199-218.

5. Hewson GM, Little LM. Giving Feedback in Medical Education Verification of Recommended Techniques. J Gen Intern Med. 1998;13(2):111116.

6. Silverman et al. The Calgary-Cambridge approach to communication skills teaching II The SET-GO method of descriptive feedback. Education for General Practice. 1997;8:16-23.

7. Brown N, Cooke L. Giving effective feedback to psychiatric trainees. Advances in psychiatric treatment. 2009;15(2);123-128.

8. Summer T, Ajjawi, Rola A, Glenn R. The "Educational Alliance" as a Framework for Reconceptualising Feedback in Medical Education. Academic Medicine. 2015;90(5):60961.

9. Cantillon P, Sargeant J. Giving feedback in clinical settings. BMJ. 2008;337(7681):1292-1294. 